\title{
Structure-antioxidant activity relationships of dendrocandin analogues determined using density functional theory
}

\author{
Ning Zhang ${ }^{1,3} \cdot$ Yilong $\mathrm{Wu}^{1,3} \cdot$ Miao Qiao ${ }^{1,3} \cdot$ Wenjuan Yuan ${ }^{1,2} \cdot$ Xingyu $\mathrm{Li}^{2} \cdot$ Xuanjun Wang ${ }^{1,2} \cdot$ Jun Sheng $^{1}$. \\ Chengting $\mathrm{Zi}^{1,2}$ (D)
}

Received: 22 December 2021 / Accepted: 9 February 2022 / Published online: 18 February 2022

(c) The Author(s), under exclusive licence to Springer Science+Business Media, LLC, part of Springer Nature 2022

\begin{abstract}
Quantum-chemical calculations based on the density functional theory (DFT) at the B3LYP/6-311+ + G(2d,2p)//B3LYP/6$31 \mathrm{G}(\mathrm{d}, \mathrm{p})$ level were employed to study the relationship between the antioxidant properties and chemical structures of six dendrocandin (DDCD) analogues in the gas phase and two solvents (methanol and water). The hydrogen atom transfer (HAT), electron-transfer-proton-transfer (ET-PT), and sequential proton-loss-electron-transfer (SPLET) mechanisms are explored. The highest occupied molecular orbital (HOMO), lowest unoccupied molecular orbital (LUMO), reactivity indices $(\eta, \mu$, $\omega, \omega^{+}$, and $\omega^{-}$), and molecular electrostatic potentials (MEPs) were also evaluated. The results suggest that the D ring plays an important role in mediating the antioxidant activity of DDCDs. For all the studied compounds, indicating that HAT was identified as the most favorable mechanism, whereas the SPLET mechanism was the most thermodynamically favorable pathway in polar solvents. The results of our study should aid in the development of new or modified antioxidant compounds.
\end{abstract}

Keywords Dendrocandin analogues $\cdot$ Radical scavenging activity $\cdot$ Structure activity relationship $\cdot$ Antioxidant mechanism $\cdot$ DFT

\section{Introduction}

Oxidative stress generated by an increase in free radical levels is a pro-oxidative state in which the reactive oxygen species (ROS) level exceeds the capability of antioxidant defense mechanisms. Oxidative stress has been linked to numerous diseases including inflammation, cancers, metabolic disorders, atherosclerosis, and Alzheimer's disease [1-6]. Antioxidant compounds protect cells against

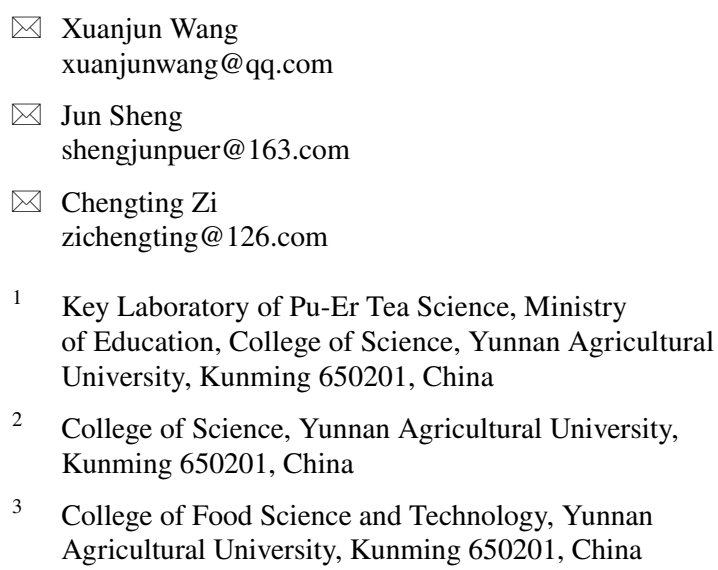

2 College of Science, Yunnan Agricultural University, Kunming 650201, China

3 College of Food Science and Technology, Yunnan Agricultural University, Kunming 650201, China

oxidative damage by scavenging free radicals and reducing ROS. Therefore, antioxidant research and development has attracted considerable attention in recent years.

Phenolic compounds constitute an important class of antioxidants, with extensive commercial and biological applications for inhibiting material oxidation [7]. The ability of phenolic compounds to scavenge free radicals depends on the number of phenolic hydroxyl groups [8]. A number of recent computational studies of antioxidation mechanisms have employed thermodynamic evaluations of various physicochemical parameters, such as bond dissociation enthalpy (BDE), ionization potential (IP), proton dissociation enthalpy (PDE), proton affinity (PA), and electron transfer enthalpy (ETE) [9-12]. In addition, DFT has been used to evaluate the chemical properties and study the structure-activity relationships (SARs) of a variety of phenolic antioxidants [9, 13-17].

Dendrocandins (DDCDs) comprise a family of compounds originally extracted from the stem of Dendrobium plants [18-23]. The structure of DDCD was elucidated as a stilbenolignan skeleton in which a bibenzyl moiety is linked to a phenylpropane unit via a dioxane bridge. DDCDs are highly bioactive, exhibiting antioxidant, anticancer, and 
anti-inflammatory activities [18-24]. As a class of important compounds in Dendrobium species, DDCDs have attracted considerable and growing interest among scientists. Recently, the studies have been published regarding the antioxidant activities of DDCDs [19, 20].

However, no DFT-based studies of the antioxidant activity of DDCDs have been reported to date. The present study therefore focused on examining the radical scavenging activity of six selected DDCDs (1-6) (Fig. 1). The objective of this research was to elucidate the radical scavenging activity relationships of these DDCDs at the DFT level in order to generate novel clues useful in antioxidant development. The B3LYP/6-311 + + G(2d,2p)//B3LYP/6-31G(d,p) level of the theory was employed to enable reliable optimization of the geometric parameters of the compounds and calculate various physicochemical descriptors of their antioxidant ability, including O-H BDE, IP, PDE, PA, and ETE. Moreover, HOMO and LUMO distributions, MEPs, and spin density in free radicals were also calculated. In this report, we hope to highlight the potent antioxidant activity of these DDCDs and stimulate interest not only in further studies but also in the exploitation of these compounds for food and pharmaceutical applications.

\section{Computational details}

According to the literature, three primary antioxidant mechanisms for scavenging of phenolic antioxidants have been reported [9, 10, 12, 25]: (1) hydrogen atom transfer (HAT);

(2) stepwise electron-transfer-proton-transfer (ET-PT); and

(3) sequential proton-loss-electron-transfer (SPLET). Equations (1)-(3) summarize these mechanisms:
$\mathrm{R}^{\bullet}+\mathrm{ArOH} \rightarrow \mathrm{RH}+\mathrm{ArO}^{\bullet}$

$\mathrm{R}^{\bullet}+\mathrm{ArOH} \rightarrow \mathrm{R}^{-}+\mathrm{ArOH}^{+\bullet} \rightarrow \mathrm{RH}+\mathrm{ArO}^{\bullet}$.

$\mathrm{ArOH} \rightarrow \mathrm{ArO}^{-}+\mathrm{R}^{+} \mathrm{ArO}^{-}+\mathrm{R}^{\cdot} \rightarrow \mathrm{ArO}^{\bullet} \cdot+\mathrm{R}^{-} \mathrm{R}^{-}+\mathrm{H}^{+} \rightarrow \mathrm{RH}$

In the HAT mechanism, the free radical $\left(\mathrm{R}^{\bullet}\right)$ reacts with the antioxidant $(\mathrm{ArOH})$ by transferring a hydrogen atom to $\mathrm{R}^{\bullet}$ via hemolytic rupture of the $\mathrm{O}-\mathrm{H}$ bond of $\mathrm{ArOH}$ to generate a radical $\left(\mathrm{ArO}^{\circ}\right)$. The reactivity of the $\mathrm{ArOH}$ can be estimated by calculating the $\mathrm{O}-\mathrm{H}$ bond BDE, the lower the BDE value. The ET-PT mechanism involves two steps: first, the $\mathrm{ArOH}$ gives an electron $\left(\mathrm{e}^{-}\right)$to $\mathrm{R}^{\bullet}$, followed by proton $\left(\mathrm{H}^{+}\right)$transfer from the radical cation $\left(\mathrm{ArOH}^{+\bullet}\right)$ to generate the free radical $\left(\mathrm{ArO}^{\bullet}\right)$. In this case, the IP and PDE are the most significant energetic factors for evaluating the scavenging activity. Molecules exhibiting low IP and PDE values are predicted to have high activity. The SPLET mechanism also involves two steps: the phenoxide anion $\left(\mathrm{ArO}^{-}\right)$is generated by loss of the proton from $\mathrm{ArOH}$ as the first step in the mechanism, then an electron of $\mathrm{ArO}^{-}$is transferred to $\mathrm{R}^{\bullet}$ to generate the radical. The SPLET mechanism is governed by the PA and ETE of the phenoxide anion. Thus, in the present study, BDE, IP, PDE, PA, and ETE values served as the primary molecular descriptors in elucidating the radical scavenging activity of the DDCDs.

From the calculated total enthalpies at $298.15 \mathrm{~K}$, the followed relationships were determined:

$$
\mathrm{BDE}=\mathrm{H}\left(\mathrm{ArO}^{\bullet}\right)+\mathrm{H}\left(\mathrm{H}^{\bullet}\right)-\mathrm{H}(\mathrm{ArOH})
$$

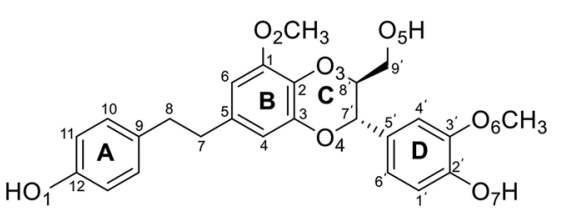

DDCD1<smiles></smiles>

DDCD4<smiles>COc1cc([C@H]2Oc3c(OC)cc(CCc4ccc(O)cc4)cc3O[C@@H]2CO)cc(O)c1O</smiles>

DDCD2<smiles>COc1cc([C@@H]2Oc3cc(CCc4ccc(O)cc4)cc(OC)c3O[C@H]2c2ccc(O)cc2)cc(O)c1O</smiles>

DDCD5<smiles>COc1ccc(CCc2cc(OC)c3c(c2)O[C@H](c2cc(O)c(O)c(OC)c2)[C@H](c2ccc(OC)cc2)O3)cc1</smiles>

DDCD3<smiles>COc1cc(C(O)C(CO)C(=O)O)ccc1OCc1cc(CCc2ccc(O)cc2)cc(OC)c1O</smiles>

DDCD6

Fig. 1 Chemical structures of the six dendrocandin (DDCD) analogues examined in the present study 
$\mathrm{IP}=\mathrm{H}\left(\mathrm{ArOH}^{\cdot+}\right)+\mathrm{H}\left(\mathrm{e}^{-}\right)-\mathrm{H}(\mathrm{ArOH})$

$\mathrm{PDE}=\mathrm{H}\left(\mathrm{ArO}^{\bullet}\right)+\mathrm{H}\left(\mathrm{H}^{+}\right)-\mathrm{H}\left(\mathrm{ArOH}^{\bullet+}\right)$

$\mathrm{PA}=\mathrm{H}\left(\mathrm{ArO}^{-}\right)+\mathrm{H}\left(\mathrm{H}^{+}\right)-\mathrm{H}(\mathrm{ArOH})$

$\mathrm{ETE}=\mathrm{H}\left(\mathrm{ArO}^{*}\right)+\mathrm{H}\left(\mathrm{e}^{-}\right)-\mathrm{H}\left(\mathrm{ArO}^{-}\right)$

The molecular enthalpy of $298.15 \mathrm{~K}$ consisted of B3LYP/6-311 + + G(2d,2p) calculated single-point energy values and $\mathrm{B} 3 \mathrm{LYP} / 6-31 \mathrm{G}(\mathrm{d}, \mathrm{p})$ thermal contributions to the enthalpy. Gas-phase correction was employed to calculate the molecular enthalpy in the aqueous phase. The calculated gas-phase enthalpy of $\mathrm{H}^{\bullet}$ predicted using the B3LYP/6-311 + + G(2d,2p) method was $-312.956 \mathrm{kcal} / \mathrm{mol}$ [12]. The gas-phase enthalpy of $\mathrm{H}^{+}$and $\mathrm{e}^{-}$were 1.483 and $0.752 \mathrm{kcal} / \mathrm{mol}$, respectively [26]. The solvation enthalpy of $\mathrm{H}^{+}$and $\mathrm{e}^{-}$were taken from reference [27], and the hydrogen atom solvation enthalpy was taken from reference [28].

All calculations were performed using GAUSSIAN 09 program package [29]. The DFT method combining the B3LYP hybrid density function was applied in this study due to its successful application in other studies of the radical scavenging activity of phenolic compounds $[8,12$, 30, 31]. To identify the starting structures with minimum energy, a conformational analysis was performed using the $6-31 \mathrm{G}(\mathrm{d}, \mathrm{p})$ basis set. After identifying the minimumenergy conformations, a further geometric optimization was performed using the B3LYP/6-311+ + G(2d,2p) level. Vibration frequencies of the optimized structures were computed at the same theoretical level. For all optimized structures, the harmonic vibrational frequencies of the corresponding bonds were calculated to determine stationary points on the potential energy surface. Effects of solvents (methanol and water) were taken into account at the single-point level by employing the self-consistent reaction field method with a polarized continuum model [32]. The HOMO and LUMO energy distributions, MEPs, and the spin density for each radical atom were determined using the B3LYP/6-311+ + G(2d,2p) level of the theory for all optimized structures of the investigated compounds. All values for the molecular descriptors are expressed in $\mathrm{kcal} / \mathrm{mol}(1$ a.u. $=627.5095 \mathrm{kcal} / \mathrm{mol})$.

\section{Results and discussion}

\section{Optimized geometries of the DDCDs}

Molecular geometries determined using theoretical methods are useful for explaining the three-dimensional structures of investigated compounds. Optimization of DDCDs
1-6 was carried out at the B3LYP/6-311+ + G(2d,2p)// B3LYP/6-31G(d,p) level of the DFT, as shown in Fig. 2, and the lengths of important bonds are listed in Table S1. The differences between DDCDs 1-6 were found in the range 0.001-0.018 ̊.

\section{HAT mechanism}

In order to characterize the radical scavenging activity of each hydroxyl group, BDE values in the gas phase and in solvents (methanol and water) were calculated at the B3LYP/6-311 + + G(2d,2p) level for every radical species resulting from removal of the hydrogen atom from each hydroxyl group. The calculated BDE values and experimental data regarding the radical scavenging activity of DDCDs 1-6 are shown in Table $1[19,33]$. From Table 1, it can be seen that $\mathrm{O}(7)-\mathrm{OH}$ has the lowest BDE for DDCDs $\mathbf{1 - 3}$ and 6, whereas $\mathrm{O}(5)-\mathrm{OH}$ in DDCD4 and DDCD5 exhibited the lowest BDE. The BDE values for DDCDs 1-6 in the gas phase assumed the following order: $\mathrm{O}(7)-\mathrm{OH}<\mathrm{O}(1)-\mathrm{OH}$, $\mathrm{O}(7)-\mathrm{OH}<\mathrm{O}(1)-\mathrm{OH}<\mathrm{O}(8)-\mathrm{OH}, \mathrm{O}(7)-\mathrm{OH}<\mathrm{O}(8)-\mathrm{OH}, \mathrm{O}(5)-$ $\mathrm{OH}<\mathrm{O}(1)-\mathrm{OH}<\mathrm{O}(8)-\mathrm{OH}<\mathrm{O}(7)-\mathrm{OH}, \mathrm{O}(5)-\mathrm{OH}<\mathrm{O}(1)-$ $\mathrm{OH}<\mathrm{O}(8)-\mathrm{OH}<\mathrm{O}(7)-\mathrm{OH}$, and $\mathrm{O}(7)-\mathrm{OH}<\mathrm{O}(1)-\mathrm{OH}$. The same sequence was obtained regarding $\mathrm{BDE}$ values in the solvents methanol and water. These results confirmed that it is more difficult to abstract the hydrogen atom from $\mathrm{O}(1)-\mathrm{OH}$ than from other $\mathrm{OH}$ groups in DDCDs $\mathbf{1 - 3}$ and $\mathbf{6}$, whereas it is more difficult to abstract the proton from $\mathrm{O}(7)$ $\mathrm{OH}$ than other $\mathrm{OH}$ groups in DDCD4 and DDCD5.

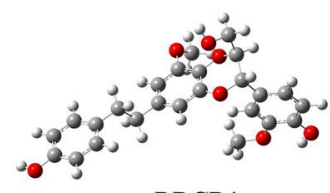

DDCD1

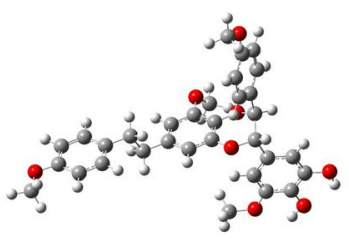

DDCD3

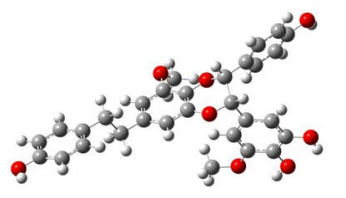

DDCD5

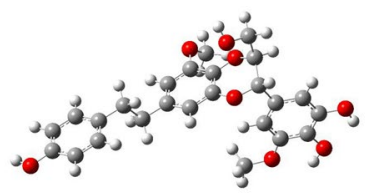

DDCD2

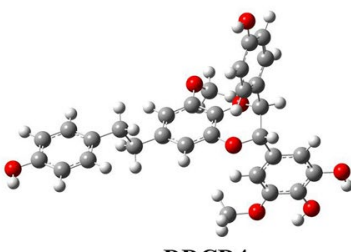

DDCD4

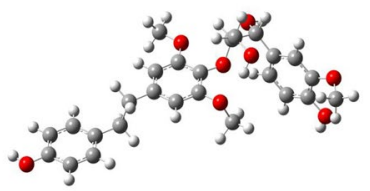

DDCD6 oxygen atom carbon atom hydrogen atom

Fig. 2 Optimized geometries of DDCDs 1-6 at the B3LYP/6$311++\mathrm{G}(2 \mathrm{~d}, 2 \mathrm{p}) / / \mathrm{B} 3 \mathrm{LYP} / 6-31 \mathrm{G}(\mathrm{d}, \mathrm{p})$ level of the DFT 
Table 1 B3LYP/6-311+ +G(2d,2p) BDE values of DDCDs 1-6 in the gas phase and three solvents

\begin{tabular}{|c|c|c|c|c|}
\hline \multirow[t]{2}{*}{ Compound } & \multicolumn{3}{|c|}{$\operatorname{BDE}^{\mathrm{a}}(\mathrm{kcal} / \mathrm{mol})$} & \multirow[t]{2}{*}{$\mathrm{IC}_{50}(\mu \mathrm{M})$} \\
\hline & Gas & Methanol & Water & \\
\hline DDCD1 & & & & 87.6 \\
\hline $\mathrm{O}(1)-\mathrm{OH}$ & 141.570 & 452.876 & 450.636 & \\
\hline $\mathrm{O}(7)-\mathrm{OH}$ & 99.526 & 409.615 & 407.322 & \\
\hline DDCD2 & & & & 50.4 \\
\hline $\mathrm{O}(1)-\mathrm{OH}$ & 97.223 & 410.076 & 407.893 & \\
\hline $\mathrm{O}(7)-\mathrm{OH}$ & 92.822 & 404.552 & 402.313 & \\
\hline $\mathrm{O}(8)-\mathrm{OH}$ & 99.894 & 410.286 & 408.007 & \\
\hline DDCD3 & & & & 21.3 \\
\hline $\mathrm{O}(7)-\mathrm{OH}$ & 92.617 & 404.468 & 402.231 & \\
\hline $\mathrm{O}(8)-\mathrm{OH}$ & 99.765 & 410.128 & 407.840 & \\
\hline DDCD4 & & & & 30.3 \\
\hline $\mathrm{O}(1)-\mathrm{OH}$ & 97.218 & 409.942 & 407.749 & \\
\hline $\mathrm{O}(5)-\mathrm{OH}$ & 92.755 & 404.532 & 402.293 & \\
\hline $\mathrm{O}(7)-\mathrm{OH}$ & 99.914 & 410.204 & 407.926 & \\
\hline $\mathrm{O}(8)-\mathrm{OH}$ & 99.027 & 412.456 & 410.296 & \\
\hline DDCD5 & & & & 22.3 \\
\hline $\mathrm{O}(1)-\mathrm{OH}$ & 97.248 & 409.944 & 407.749 & \\
\hline $\mathrm{O}(5)-\mathrm{OH}$ & 92.789 & 404.739 & 402.508 & \\
\hline $\mathrm{O}(7)-\mathrm{OH}$ & 99.635 & 409.932 & 407.636 & \\
\hline $\mathrm{O}(8)-\mathrm{OH}$ & 98.710 & 411.926 & 409.753 & \\
\hline DDCD6 & & & & 60.5 \\
\hline $\mathrm{O}(1)-\mathrm{OH}$ & 97.567 & 409.945 & 407.737 & \\
\hline $\mathrm{O}(7)-\mathrm{OH}$ & 95.504 & 409.250 & 407.103 & \\
\hline Trolox & 75.630 & 388.098 & 385.894 & 73.7 \\
\hline
\end{tabular}

${ }^{\mathrm{a}} 1$ a.u. $=627.5095 \mathrm{kcal} / \mathrm{mol}$

${ }^{\mathrm{b}} 50 \%$ inhibition concentration in 1,1-diphenyl-2-picrylhydrazyl (DPPH) assay, see Ref. [19, 33]

Analysis of the data in Table 1 shows that the BDE values decrease in the order DDCD1 $>$ DDCD6 $>$ DDCD2 $>$ DDC D4 $>$ DDCD5 $>$ DDCD3 in both the gas and solvent phases, so the sequence of hydrogen donating ability is as follows: DDCD3 $>$ DDCD5 $>$ DDCD4 $>$ DDCD2 $>$ DDCD6 $>$ DDC D1. DDCD3 is always the most active of the investigated compounds, independent of medium. The predicted order of hydrogen donating ability based on BDE values was in line with DPPH assay experimental results [19, 33].

Spin density is often considered a realistic parameter to evaluate in rationalizing the stability of radical species [34-36]. Generally, the more delocalized the spin density of the radical, the easier the radical will be formed, and thus, the lower will be the BDE [37]. In order to rationalize the differences in $\mathrm{BDE}$ and reactivity of the $\mathrm{OH}$ sites, the spin density distributions of the radicals were calculated (Fig. 3). As depicted in Fig. 3, the spin densities of all radicals appeared to be distributed more in the A-, D-ring than the other rings. The spin densities of the $\mathrm{O}$-atoms of the $\mathrm{O}(1)-\mathrm{OH}$ radicals in DDCD1, DDCD4, and DDCD6 were $0.675,0.614$, and 0.616 , respectively. This suggested that stabilization of these radicals was in the order DDCD1 $>$ DDCD6 $>$ DDCD4, with the $\mathrm{BDE}$ values of $\mathrm{O}(1)-\mathrm{OH}$ increasing in the same order. The spin density was 0.675 for the $\mathrm{O}$-atom in the $\mathrm{O}(1)$ of DDCD1, whereas it was 0.580 for the $\mathrm{O}(7)-\mathrm{OH}$ radical. Therefore, the $\mathrm{BDE}$ value was lower in the $\mathrm{D}$ ring than the A ring. By comparison, the spin densities of the $\mathrm{O}(7)-\mathrm{OHs}$ for DDCD3 and DDCD4 were 0.536 and 0.537, lower than the densities of other phenolic radicals. This could explain why DDCD3-O7 and DDCD4-O7 exhibited lower BDE values than the other compounds. The spin population also explains the difference between $\mathrm{O}(1)-\mathrm{OH}$ and $\mathrm{O}(7)-\mathrm{OH}$ in terms of antioxidant activity. As can be seen from Fig. 3, the spin densities of the DDCD1 and DDCD6 were mainly distributed in the phenolic oxygen and A- and B-rings.

As shown in Table 1, the solvent had different effects on the BDE value for each compound. In general, BDE tended to increase from the gas phase to solvent phase. However, the BDE values were similar in all studied solvent environments for each compound. A decrease of 3.156-4.721 kcal/mol in BDE values was observed when computations were carried out in water solvent. All BDE values in water were lower than those in other solvents. Lengyel et al. [38] reported a similar trend in BDE values for isoflavones.

For DDCDs 2-5, which possess ortho-dihydroxy groups on the D ring, lower BDE values (92.617-99.894 kcal/ mol) were observed in the gas phase compared with BDE values of the other two compounds with no such groups (95.504-141.570 kcal/mol). For DDCD2 and DDCD3, if the $\mathrm{H}$-atom was abstracted from the hydroxyl group $(\mathrm{O}(7)$ $\mathrm{OH}$ ), a relatively strong $\mathrm{O}-\mathrm{H}^{\cdots} \mathrm{H}$ hydrogen bond was formed that stabilized the phenoxy radical (Fig. S1). A similar phenomenon was observed in a previous study [8]. As shown in Table 1, the BDE values of $\mathrm{O}(7)-\mathrm{OH}$ in DDCD3 were $92.617,406.134,404.468$, and $402.231 \mathrm{kcal} / \mathrm{mol}$ in the gas phase and solvents methanol, and water, respectively. These values were lower than the corresponding values for $\mathrm{O}(7)$ $\mathrm{OH}$ in the other compounds. These data clearly confirm that HAT occurs more readily from $\mathrm{O}(7)-\mathrm{OH}$ than other hydroxyl groups, and thus, $\mathrm{O}(7)-\mathrm{OH}$ is considered to be the main target of free radical attack.

Table 1 shows that the lowest BDE values of the DDCDs in the gas phase and solvent environments were greater than those of trolox calculated at the same theory level, indicating that the activity of the DDCDs should be comparable to that of trolox. However, this predicted trend is different from the experimental results of the DPPH tests. Values from the DPPH assay (Table 1) indicated that DDCDs 2-5 exhibit lower activity than trolox. This observed deviation could be attributed to the more general nature of the theoretical results, which do not consider all possible particular radical counterparts or the complexity of the DPPH assay mechanism [8]. 
Fig. 3 Plots of spin densities in the radicals formed by H-removal from the A-, D-, and E-rings of DDCDs 1-6 at the B3LYP/6-311 + + G(2d,2p) level of the theory in the gas phase. Green and blue regions denote positive and negative density, respectively (isovalue $=0.002$ )

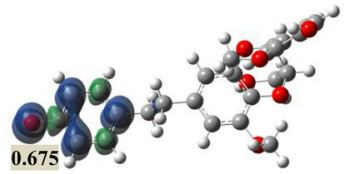

DDCD1-01
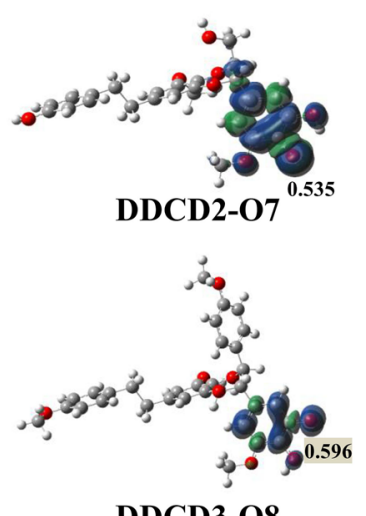

DDCD3-08

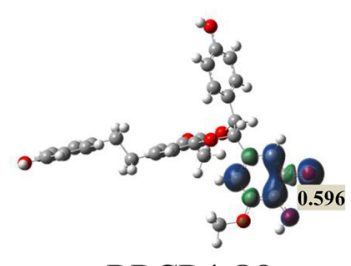

DDCD4-08

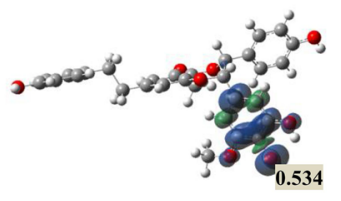

DDCD5-07

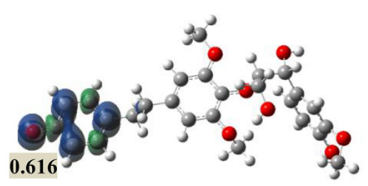

DDCD6-01

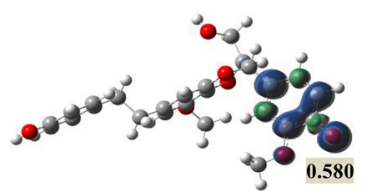

DDCD1-07

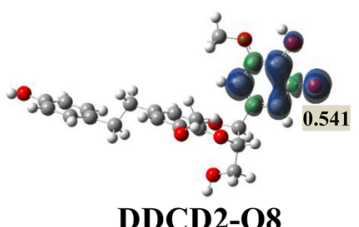

DDCD2-08

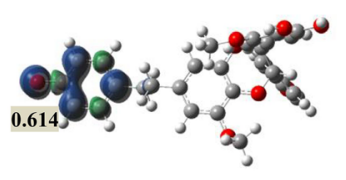

DDCD4-01

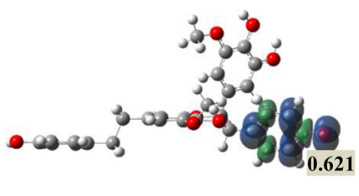

DDCD4-O9

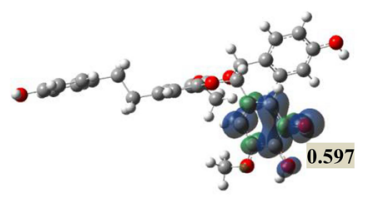

DDCD5-08

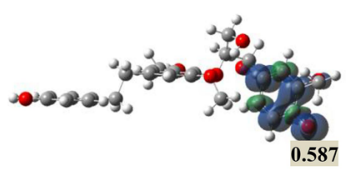

DDCD6-07

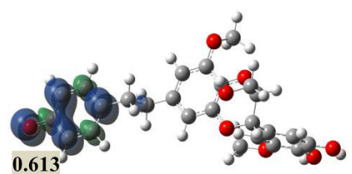

DDCD2-01

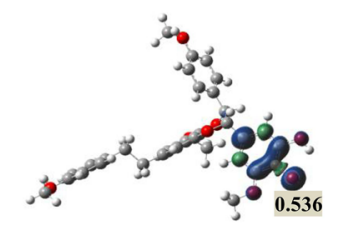

DDCD3-07

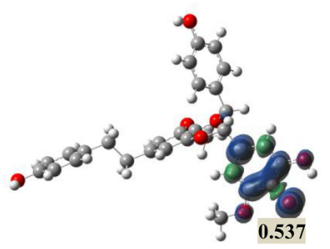

DDCD4-07

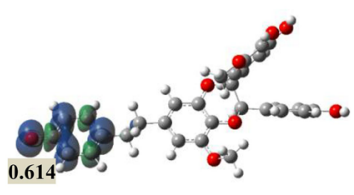

DDCD5-01

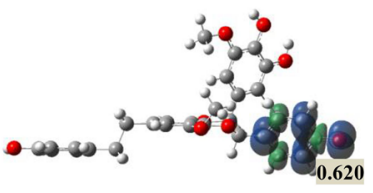

DDCD5-09

\section{SEP-PT mechanism}

Antioxidant activity can be governed by the SEP-PT mechanism [8, 37]. The calculated IPs and PDEs in the gas phase and solvents for the DDCDs are shown in Table 2. It can be seen that DDCD3 exhibited the lowest IP values in all studied media, indicating that the electron-donating capability of DDCD3 is stronger than others. The IPs in the gas phase increased in the order DDCD3 $<$ DDCD2 $<$ DDCD1 $<$ DDCD4 < DDCD5 < DDCD6. The IP values in methanol and water increased in the order DDCD1 $<\mathrm{D}$ DCD2 < DDCD3 < DDCD5 < DDCD4 < DDCD6, somewhat different from the gas phase values (see Table 2). The trend of IP values was obviously different from that

of BDE values; this discrepancy can be attributed to the observation that the BDE is affected by the local environment caused by the substituents, where the IP is affected by the entire molecular structure [10].

As shown in Table 2, the solvent had differing effects on IP values. DDCD3 exhibited the highest radical scavenging activity, with $\mathrm{IC}_{50}$ values ranging from 109.618 to $159.408 \mathrm{kcal} / \mathrm{mol}$ in going from the gas phase to water as a solvent. An analysis of the data in Table 2 showed that the IP values in solvents were significantly lower than those in the gas phase. The IPs declined in the environmental order gas $>$ methanol $>$ water, confirming that cation radicals are charged and quite sensitive to solvent polarity, in agreement with a previous report [8]. In addition, the IPs of DDCDs 
Table 2 B3LYP/6-

$311++\mathrm{G}(2 \mathrm{~d}, 2 \mathrm{p})$ IP and PDE values of DDCDs 1-6 in the gas phase and various solvents

\begin{tabular}{|c|c|c|c|c|c|c|}
\hline \multirow[t]{2}{*}{ Compound } & \multicolumn{3}{|c|}{ IP (kcal/mol) } & \multicolumn{3}{|c|}{$\mathrm{PDE}(\mathrm{kcal} / \mathrm{mol})$} \\
\hline & Gas & Methanol & Water & Gas & Methanol & Water \\
\hline DDCD1 & 160.350 & 112.725 & 107.696 & & & \\
\hline $\mathrm{O}(1)-\mathrm{OH}$ & & & & 297.159 & 70.932 & 75.155 \\
\hline $\mathrm{O}(7)-\mathrm{OH}$ & & & & 255.114 & 27.671 & 31.841 \\
\hline DDCD2 & 159.852 & 112.872 & 107.865 & & & \\
\hline $\mathrm{O}(1)-\mathrm{OH}$ & & & & 253.347 & 28.022 & 32.281 \\
\hline $\mathrm{O}(7)-\mathrm{OH}$ & & & & 248.945 & 22.499 & 26.701 \\
\hline $\mathrm{O}(8)-\mathrm{OH}$ & & & & 256.018 & 28.233 & 32.394 \\
\hline DDCD3 & 159.408 & 114.582 & 109.618 & & & \\
\hline $\mathrm{O}(7)-\mathrm{OH}$ & & & & 249.320 & 20.840 & 25.002 \\
\hline $\mathrm{O}(8)-\mathrm{OH}$ & & & & 256.468 & 26.500 & 30.611 \\
\hline DDCD4 & 161.526 & 114.919 & 109.907 & & & \\
\hline $\mathrm{O}(1)-\mathrm{OH}$ & & & & 251.763 & 25.938 & 30.191 \\
\hline $\mathrm{O}(5)-\mathrm{OH}$ & & & & 247.301 & 20.528 & 24.736 \\
\hline $\mathrm{O}(7)-\mathrm{OH}$ & & & & 254.459 & 26.200 & 30.358 \\
\hline $\mathrm{O}(8)-\mathrm{OH}$ & & & & 253.573 & 28.451 & 32.738 \\
\hline DDCD5 & 161.840 & 114.726 & 109.658 & & & \\
\hline $\mathrm{O}(1)-\mathrm{OH}$ & & & & 251.480 & 26.133 & 30.440 \\
\hline $\mathrm{O}(5)-\mathrm{OH}$ & & & & 247.021 & 20.928 & 25.200 \\
\hline $\mathrm{O}(7)-\mathrm{OH}$ & & & & 253.867 & 26.121 & 30.327 \\
\hline $\mathrm{O}(8)-\mathrm{OH}$ & & & & 252.942 & 28.114 & 32.444 \\
\hline DDCD6 & 165.199 & 118.512 & 113.511 & & & \\
\hline $\mathrm{O}(1)-\mathrm{OH}$ & & & & 248.364 & 22.272 & 26.500 \\
\hline $\mathrm{O}(7)-\mathrm{OH}$ & & & & 246.301 & 21.577 & 25.866 \\
\hline Trolox & 149.428 & 92.322 & 87.142 & 241.816 & 26.232 & 30.642 \\
\hline
\end{tabular}

1-6 in gas were approximately $9.98-15.771 \mathrm{kcal} / \mathrm{mol}$ higher than that of trolox $(149.428 \mathrm{kcal} / \mathrm{mol})$. This means that DDCDs 1-6 exhibit weaker electron-donating ability than trolox.

As shown in Table 2, the lowest PDE values of DDCDs 1-6 in the gas phase can be arranged in the following order: DDCD $5<$ DDCD $4<$ DDCD $3<$ DDCD $2<$ DDCD $1<$ DDC D6. The PDE values in methanol and water increased in the order DCD4 $<$ DDCD3 $<$ DDCD5 $<$ DDCD6 $<$ DDCD2 $<$ DDCD1. The orders in the solvents differed somewhat from that in the gas phase. Furthermore, the lowest PDE values of DDCDs 2-6 in the studied solvents (methanol and water) were lower than trolox. This indicates that the protondissociating abilities of DDCDs 2-6 are slightly stronger than trolox, similar to the DPPH radical scavenging activity.

\section{SPLET mechanism}

Previous studies confirmed that the SPLET mechanism plays a significant role in antioxidant activity [10, 39, 40]. The PA and ETE values in the gas phase and solvents for the studied DDCDs are summarized in Table 3. The data in
Table 3 indicate the following order for the PA values of the DDCDs in all media: $\mathrm{O}(7)-\mathrm{OH}<\mathrm{O}(1)-\mathrm{OH}, \mathrm{O}(7)-\mathrm{OH}<\mathrm{O}(8)-$ $\mathrm{OH}<\mathrm{O}(1)-\mathrm{OH}, \mathrm{O}(7)-\mathrm{OH}<\mathrm{O}(8)-\mathrm{OH}, \mathrm{O}(5)-\mathrm{OH}<\mathrm{O}(8)-$ $\mathrm{OH}<\mathrm{O}(7)-\mathrm{OH}<\mathrm{O}(1)-\mathrm{OH}, \mathrm{O}(5)-\mathrm{OH}<\mathrm{O}(8)-\mathrm{OH}<\mathrm{O}(1)-$ $\mathrm{OH}<\mathrm{O}(7)-\mathrm{OH}$, and $\mathrm{O}(7)-\mathrm{OH}<\mathrm{O}(1)-\mathrm{OH}$. The $\mathrm{O}(1)-\mathrm{OH}$ PAs were higher than those of the other hydroxyl groups in all studied environments, clearly showing that formation of $\mathrm{O}(1)-\mathrm{O}^{-}$is more difficult than formation of other anions. The data in Table 3 also indicate the following order for the lowest PA values: DDCD $5<$ DDCD $3<$ DDCD $4<$ DDCD $2<$ DDCD $6<\mathrm{DDCD} 1$ in the media. The PA of $\mathrm{O}(7)-\mathrm{OH}$ is weaker than that of the other $\mathrm{OH}$ groups, except for DDCD4 and DDCD5.

Similar to PDE values, the PA values decreased significantly from the gas phase to solvent phase owing to the high solvation enthalpy of the protons. The average differences between the PA in the gas phase and different solvents were 301.97 (methanol) and 299.386 (water) kcal/ mol, respectively. This suggests that these solvents favor the deprotonation process. Additionally, the lowest gasphase PAs (354.246-362.579 $\mathrm{kcal} / \mathrm{mol})$ were greater than trolox $(347.936 \mathrm{kcal} / \mathrm{mol})$. This means that deprotonation of phenolic-OH is more difficult than deprotonation of trolox. 
Table 3 B3LYP/6-

$311++\mathrm{G}(2 \mathrm{~d}, 2 \mathrm{p})$ PA and ETE values of DDCDs $1-6$ in the gas phase and various solvents

\begin{tabular}{|c|c|c|c|c|c|c|}
\hline \multirow[t]{2}{*}{ Compound } & \multicolumn{3}{|c|}{$\mathrm{PA}(\mathrm{kcal} / \mathrm{mol})$} & \multicolumn{3}{|c|}{ ETE (kcal/mol) } \\
\hline & Gas & Methanol & Water & Gas & Methanol & Water \\
\hline \multicolumn{7}{|l|}{ DDCD1 } \\
\hline $\mathrm{O}(1)-\mathrm{OH}$ & 406.401 & 101.972 & 104.564 & 51.108 & 81.685 & 8.590 \\
\hline $\mathrm{O}(7)-\mathrm{OH}$ & 364.248 & 60.740 & 63.284 & 51.216 & 79.656 & 7.429 \\
\hline \multicolumn{7}{|l|}{ DDCD2 } \\
\hline $\mathrm{O}(1)-\mathrm{OH}$ & 363.414 & 60.243 & 62.891 & 49.785 & 80.651 & 8.107 \\
\hline $\mathrm{O}(7)-\mathrm{OH}$ & 356.170 & 56.390 & 59.045 & 52.628 & 78.980 & 9.772 \\
\hline $\mathrm{O}(8)-\mathrm{OH}$ & 363.834 & 59.553 & 62.091 & 52.036 & 81.552 & 7.801 \\
\hline \multicolumn{7}{|l|}{ DDCD3 } \\
\hline $\mathrm{O}(7)-\mathrm{OH}$ & 355.813 & 56.214 & 58.869 & 52.915 & 79.208 & 12.388 \\
\hline $\mathrm{O}(8)-\mathrm{OH}$ & 363.763 & 59.422 & 61.935 & 52.114 & 81.659 & 10.047 \\
\hline \multicolumn{7}{|l|}{ DDCD4 } \\
\hline $\mathrm{O}(1)-\mathrm{OH}$ & 362.130 & 60.085 & 62.763 & 51.159 & 80.771 & 9.237 \\
\hline $\mathrm{O}(5)-\mathrm{OH}$ & 355.223 & 56.207 & 58.875 & 53.603 & 79.240 & 10.688 \\
\hline $\mathrm{O}(7)-\mathrm{OH}$ & 363.172 & 59.411 & 61.944 & 52.813 & 81.707 & 8.362 \\
\hline $\mathrm{O}(8)-\mathrm{OH}$ & 357.879 & 57.901 & 60.550 & 57.220 & 85.469 & 16.036 \\
\hline \multicolumn{7}{|l|}{ DDCD5 } \\
\hline $\mathrm{O}(1)-\mathrm{OH}$ & 362.579 & 60.127 & 62.783 & 50.740 & 80.732 & 8.593 \\
\hline $\mathrm{O}(5)-\mathrm{OH}$ & 354.246 & 56.016 & 58.688 & 54.616 & 79.637 & 11.687 \\
\hline $\mathrm{O}(7)-\mathrm{OH}$ & 363.202 & 59.618 & 62.103 & 52.504 & 81.228 & 7.8575 \\
\hline $\mathrm{O}(8)-\mathrm{OH}$ & 357.988 & 58.287 & 60.936 & 56.794 & 84.553 & 15.189 \\
\hline \multicolumn{7}{|l|}{ DDCD6 } \\
\hline $\mathrm{O}(1)-\mathrm{OH}$ & 360.621 & 59.858 & 62.563 & 52.943 & 80.926 & 9.535 \\
\hline $\mathrm{O}(7)-\mathrm{OH}$ & 358.827 & 58.401 & 61.064 & 52.674 & 81.688 & 10.695 \\
\hline Trolox & 347.936 & 47.528 & 50.170 & 43.308 & 71.025 & 67.615 \\
\hline
\end{tabular}

The ETE values in Table 3 indicate that the lowest ETEs in the gas phase follow the order: DDCD $1<$ DDCD3 $<\mathrm{D}$ DCD $2<$ DDCD6 < DDCD4 < DDCD5. The PA values in methanol increased in the order DDCD $2<$ DDCD3 $<$ DDC D1 $<$ DDCD6 < DDCD5 <DDCD4, whereas the trend in PA values in water was DDCD1 $<$ DDCD $2<$ DDCD6 $<$ DDCD5 $<$ DDCD4 $<$ DDCD3. The differences between ETEs in the gas phase and polar solvents (methanol and water) resided in 22.021-30.577 and 40.527-44.646 kcal/mol intervals for methanol and water, respectively. Compared with the IP values (Table 2) of the neutral forms, we found that the ETE values were significantly lower in both the gas phase and solvents. The HAT, SET-PT, and SPLET mechanisms are considered the primary molecular descriptors for elucidating the thermodynamically preferred reaction pathway involved in the free radical-scavenging process. The above discussion demonstrates that the IPs and PAs of the DDCDs in the gas phase are significantly higher than the BDE values, meaning that HAT is the thermodynamically dominant process in the gas phase. The PAs of the DDCDs were lower than BDE and IP values, indicating that deprotonation is favored in polar medium (methanol and water). However, the mechanism by which an antioxidant exerts activity is not only determined by the chemical property of the antioxidants but also on the microenvironment. Elucidating the mechanism in greater detail for confirmation will require data pertaining to rate constants and branching ratios.

\section{Frontier molecular orbitals}

Spin density frontier molecular orbital analysis is useful for describing the activity of phenolic antioxidants in scavenging free radicals $[7,41]$. Two factors that significantly affect bioactivity are the HOMO and LUMO [7, 42-44]. We therefore generated plots of the HOMO and LUMO for each group to analyze the primary atomic contributions to these orbitals. The HOMO and LUMO of DDCDs $\mathbf{1 - 6}$ were explored at the B3LYP/6-311+ + G(2d,2p) level of the DFT. According to the results shown in Fig. 4 and Table 2, DDCD1 exhibited the highest HOMO energy in comparison with DDCDs 2-6, indicating that DDCD1 has the strongest electron-donating capability of these DDCDs. As depicted in Fig. 4, the $\pi$-clouds in the HOMOs of DDCDs 1-6 are distributed on the A-, B-, and D-rings, and the $\pi$-clouds in the LUMOs of DDCDs $\mathbf{1 - 5}$ are distributed on the D- and E-rings. Furthermore, the HOMOs are primarily located on the $\mathrm{O}(1)-\mathrm{OH}$ and D-ring. The D-ring makes the greatest contribution to the HOMO of DDCD6. Thus, the free radical reaction occurs primarily on the A- and D-rings. 
Fig. 4 HOMO and LUMO distributions for neutral forms of DDCDs 1-6 computed at the B3LYP/6-311+ + G(2d,2p) level of the theory in the gas phase. Green and red regions denote positive and negative orbital phases, respectively (isovalue $=0.02$ )

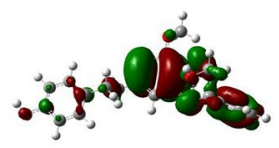

DDCD1 (HOMO)

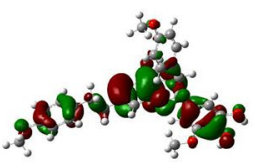

DDCD3 (HOMO)

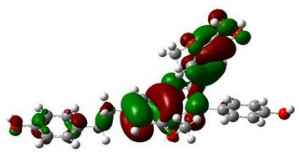

DDCD5 (HOMO)

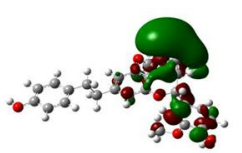

DDCD1 (LUMO)

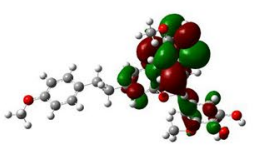

DDCD3 (LUMO)

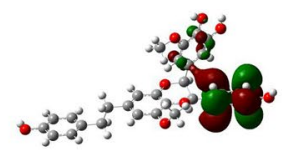

DDCD5 (LUMO)

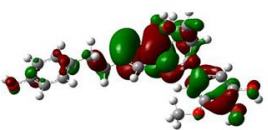

DDCD2 (HOMO)

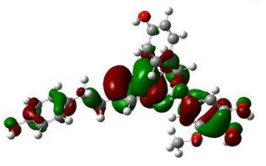

DDCD4 (HOMO)

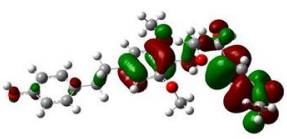

DDCD6 (HOMO)

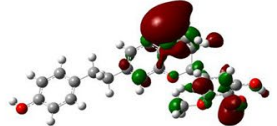

DDCD2 (LUMO)

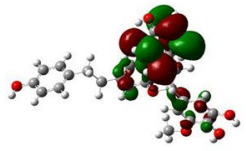

DDCD4 (LUMO)

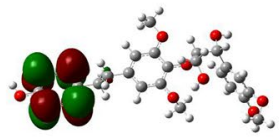

DDCD6 (LUMO)
The HOMO and LUMO energies of DDCDs 1-6 along with $\Delta E_{\text {(LUMO-HOMO) }}$ are listed in Table 4 . Among them, DDCD1 exhibited the lowest energy gap (106.049 kcal/ mol), whereas DDCD3 exhibited the largest energy gap $(124.247 \mathrm{kcal} / \mathrm{mol})$. To further confirm that reactivity indices affect the antioxidant activity, chemical hardness $(\eta)$, electronic chemical potential $(\mu)$, electrophilicity $(\omega)$, electron acceptor power $\left(\omega^{+}\right)$, and electron donor power $\left(\omega^{-}\right)$are generally considered to provide a better and more realistic representation of the reactivity and stability of a compound than other parameters. The reactivity indices of DDCDs 1-6 were calculated and listed in Table 5. As can be seen from Table 5, DDCD3 has the lowest value of $\eta(-61.496 \mathrm{kcal} /$ mol), whereas DDCD1 has the highest value $(-53.338 \mathrm{kcal} /$ $\mathrm{mol}$ ). These findings are consistent with the $\Delta E_{\text {(LUMO-HOMO) }}$ of these compounds. DDCD3 has the lowest electronic chemical potential $(-77.184 \mathrm{kcal} / \mathrm{mol})$, whereas DDCD1 has the highest electronic chemical potential $(-59.613 \mathrm{kcal} /$ mol). Furthermore, among the studied compounds, DDCD1 has the lowest $\omega^{+}$and $\omega^{-}$values $(10.040 \mathrm{kcal} / \mathrm{mol}$ and $69.654 \mathrm{kcal} / \mathrm{mol}$, respectively), whereas DDCD3 has the highest $\omega^{+}$and $\omega^{-}$values $(17.570 \mathrm{kcal} / \mathrm{mol}$ and $94.754 \mathrm{kcal} /$ mol, respectively). These results indicate that DDCD3 is

Table $4 E_{\mathrm{HOMO}}, E_{\mathrm{LUMO}}$, and $\Delta E_{\text {(LUMO-HOMO) }}$ values for DDCDs 1-6

\begin{tabular}{llll}
\hline Compound & \multicolumn{3}{l}{$E^{\mathrm{a}}(\mathrm{kcal} / \mathrm{mol})$} \\
\cline { 2 - 4 } & $E_{\text {HOMO }}$ & $E_{\text {LUMO }}$ & $\Delta E_{\text {(LUMO-HOMO) }}$ \\
\hline DDCD1 & -112.314 & -6.275 & 106.049 \\
DDCD2 & -126.129 & -14.432 & 111.697 \\
DDCD3 & -138.680 & -15.688 & 124.247 \\
DDCD4 & -134.287 & -15.688 & 118.599 \\
DDCD5 & -134.915 & -15.688 & 119.227 \\
DDCD6 & -127.384 & -14.433 & 112.952 \\
\hline
\end{tabular}

${ }^{\mathrm{a}} 1$ a.u. $=627.5095 \mathrm{kcal} / \mathrm{mol}$ weakly nucleophilic, whereas DDCD1 is strongly electrophilic in nature.

\section{MEPs}

Measurement of spin density MEP is a very useful approach for exploring the reactivity and structure-activity relationships of compounds [45-47]. A previous study used the MEP to characterize the antioxidant activity of catechin derivatives [48]. To further elucidate the structure-antioxidant activity relationships of DDCDs 1-6, MEP analyses were carried out for the lowest-energy conformers to characterize the similarity and dissimilarity in the electrostatic binding characteristics of the surface of the molecules (Fig. 5). The results clearly indicated that the electronic density in DDCD1 is concentrated in the oxygen of the $\mathrm{O}(1)-\mathrm{OH}$ in the A-ring, which is directly attached to the benzene ring. In addition, the protons attached to the A-ring are in electron-rich sites. A similar trend was

Table 5 Reactivity indices of DDCDs 1-6

\begin{tabular}{llllll}
\hline Compound & \multicolumn{6}{l}{ Reactivity index $(\mathrm{kcal} / \mathrm{mol})$} \\
\cline { 2 - 6 } & $\eta^{\mathrm{b}}$ & $\mu^{\mathrm{c}}$ & $\omega^{\mathrm{d}}$ & $\omega^{+\mathrm{e}}$ & $\omega^{-\mathrm{f}}$ \\
\hline DDCD1 & -0.085 & -0.095 & -0.053 & 0.016 & 0.111 \\
DDCD2 & -0.089 & -0.112 & -0.071 & 0.026 & 0.138 \\
DDCD3 & -0.098 & -0.123 & -0.080 & 0.028 & 0.151 \\
DDCD4 & -0.095 & -0.120 & -0.076 & 0.028 & 0.147 \\
DDCD5 & -0.095 & -0.120 & -0.076 & 0.028 & 0.148 \\
DDCD6 & -0.090 & -0.113 & -0.070 & 0.026 & 0.139 \\
\hline
\end{tabular}

${ }^{\mathrm{a}} 1$ a.u. $=627.5095 \mathrm{kcal} / \mathrm{mol}$

${ }^{\mathrm{b}} \eta=\left(E_{\mathrm{HOMO}}-E_{\mathrm{LUMO}}\right) / 2$

${ }^{\mathrm{c}} \mu=\left(E_{\mathrm{HOMO}}+E_{\mathrm{LUMO}}\right) / 2$

${ }^{\mathrm{d}} \omega=\mu^{2} / 2 \eta$

${ }^{\mathrm{e}} \omega^{+}=(I+3 A)^{2} / 16(I-A)$

${ }^{\mathrm{f}} \omega^{-}=(3 I+A)^{2} / 16(I-A), I \approx-E_{\mathrm{HOMO}}, A \approx-E_{\mathrm{LUMO}}$ 


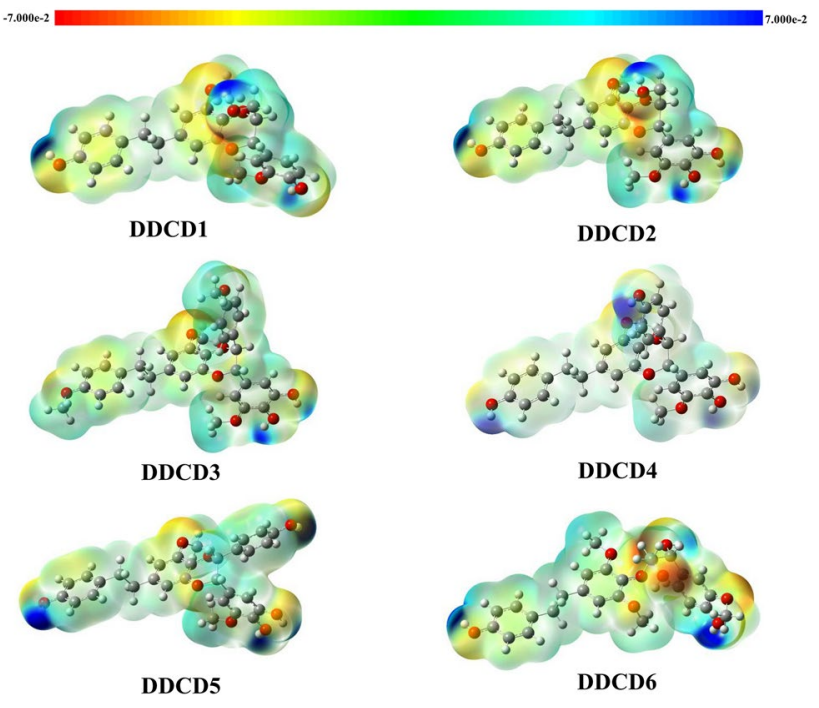

Fig. 5 Graphical depiction of molecular electrostatic potentials of DDCDs 1-6 (red = intense electron-rich site, yellow = medium electron-rich site, blue $=$ electron-deficient site, light green $=$ almost neutral site, grey $=$ white $=$ zero potential)

observed for DDCD2 and DDCD6, but DDCD3 exhibited localization of extra electronic density on methoxy groups in the A-ring. In compounds DDCD4 and DDCD5, the electronic density was more dispersed on the A-, D-, and E-rings.

\section{Conclusions}

In summary, the B3LYP/6-311+ + G(2d,2p)// B3LYP/6-31(d,p) level of the DFT was applied to study the radical scavenging activity of six DDCD analogues. Thermodynamic parameters such as BDE, IP, PDE, PA, and ETE were computed for DDCDs 1-6 in the gas phase and in solvents (methanol and water) to evaluate the possible mechanism. In addition, other descriptors, such as HOMO distribution, reactivity indices $\left(\eta, \mu, \omega, \omega^{+}\right.$, and $\left.\omega^{-}\right)$, spin density, and MEP were also computed. The theoretical results of the study confirm the important role of the D-ring in mediating the antioxidant activity of these DDCDs. It can be concluded that HAT is the most favored mechanism for explaining the radical scavenging activity of the DDCDs, whereas the SPLET mechanism is favored in polar solvents (methanol and water). Among the compounds studied, DDCD3 was predicted to be a potential free-radical scavenger and thus warrants further exploitation as a candidate antioxidant. The results of our study not only enhance understanding of the antioxidant activity of DDCDs but should also stimulate further research to exploit these compounds in the food chemistry and pharmaceutical fields.

Supplementary Information The online version contains supplementary material available at https://doi.org/10.1007/s11224-022-01895-2.
Author contribution Ning Zhang and Yilong Wu contributed equally to this work. Ning Zhang: conceptualization, data curation, formal analysis, investigation, methodology, project administration, visualization, writing - original draft, reviewing, and editing. Yilong Wu: conceptualization, data curation, formal analysis, investigation, methodology, project administration, visualization, writing — original draft, reviewing, and editing. Miao Qiao: conceptualization, investigation, methodology, reviewing, and editing. Wenjuan Yuan: conceptualization, investigation, methodology, visualization, reviewing, and editing. Xingyu Li: conceptualization, investigation, methodology, reviewing, and editing. Xuanjun Wang: conceptualization, formal analysis, methodology, project administration, resources, supervision, writing-review and editing. Jun Sheng: conceptualization, formal analysis, methodology, project administration, resources, supervision, writing-review and editing. Chengting $\mathrm{Zi}$ : conceptualization, data curation, formal analysis, investigation, methodology, project administration, visualization, writing — original draft, reviewing, and editing.

Funding This work was supported by the National Nature Science Foundation of China (31960075), the Yunnan Provincial Science and Technology Department (2017ZF003), and the Yunnan provincial key programs of the Yunnan Eco-friendly Food International Cooperation Research Center Project (2019ZG00904, 2019ZG00909).

Code availability ChemDraw Ultra 7.0, Discovery Studio 4.0, GaussView 5.0.

\section{Declarations}

Consent to publish All authors whose names appear on the submission approved the version to be published.

Competing interests The authors declare no competing interests.

\section{References}

1. Bandyopadhyay U, Das D, Banerjee RK (1999) Reactive oxygen species: oxidative damage and pathogenesis. Curr Sci 77:658-666

2. Finkel T (2005) Radical medicine: treating ageing to cure disease. Nat Rev Mol Cell Biol 6:971-976

3. Finkel T, Holbrook NJ (2000) Oxidants, oxidative stress and the biology of ageing. Nature 408:239-247

4. Goldstein BD, Witz G (1990) Free radicals and carcinogenesis. Free Radical Res 11:3-10

5. Farbstein D, Kozak-Blickstein A, Levy AP (2010) Antioxidant vitamins and their use in preventing cardiovascular disease. Molecules 15:8098

6. Pieta PG (2000) Flavonoids as antioxidants. J Nat Prod 63:1035-1042

7. Xue YS, Zhang L, Li YL, Yu S, Zheng YG, An L, Gong XD, Lium Y (2013) A DFT study on the structure and radical scavenging activity of newly synthesized hydroxychalcones. J Phys Org Chem 26:240-248

8. Wang GR, Xue YS, An L, Zheng YG, Dou YY, Zhang L, Liu Y (2015) Theoretical study on the structural and antioxidant properties of some recently synthesised 2,4,5-trimethoxy chalcones. Food Chem 171:89-97

9. Leopoldini M, Russo N, Toscano M (2011) The molecular basis of working mechanism of natural polyphenolic antioxidants. Food Chem 125:288-306

10. Wright JS, Johnson ER, DiLabio GA (2001) Predicting the activity of phenolic antioxidants: theoretical method, analysis of substituent effects, and application to major families of antioxidants. J Am Chem Soc 123:1173-1183 
11. Kumar KS, Kumaresan R (2012) A DFT study on the structural, electronic properties and radical scavenging mechanisms of calycosin, glycitein, pratensein and prunetin. Comput Theoret Chem 985:14-22

12. Nenadis N, Tsimidou MZ (2012) Contribution of DFT computed molecular descriptors in the study of radical scavenging activity trend of natural hydroxybenzaldehydes and corresponding acids. Food Res Int 48:538-543

13. Sadasivama K, Kumaresan R (2011) A comparative DFT study on the antioxidant activity of apigenin and scutellarein flavonoid compounds. Mol Phys 109:839-852

14. Nazifi SMR, Asgharshamsi MH, Dehkordi MM, Zborowski KK (2019) Antioxidant properties of Aloe vera components: a DFT theoretical evaluation. Free Radical Res 53:922-931

15. Liu YY, Liu CQ, Li JJ (2020) Comparison of vitamin C and its derivative antioxidant activity: evaluated by using density functional theory. ACS Omega 5:25467-25475

16. Liu YY, Lv K, Z, Li Y, Nan QL, Xu JY, (2018) Synthesis, fungicidal activity, structure-activity relationships (SARs) and density functional theory (DFT) studies of novel strobilurin analogues containing arylpyrazole rings. Sci Rep 8:7822

17. Reddy GM, Jr AC, Garcia JR (2020) Pyrrole-2,5-dione analogs as a promising antioxidant agents: microwave-assisted synthesis, bio-evaluation, SAR analysis and DFT studies/interpretation. Bioorg Chem 106:104465

18. Yang L, Liu J, Luo HR, Cui J, Zhou J, Wang XJ, Sheng J, Hu JM (2015) Two new dendrocandins with neurite outgrowthpromoting activity from Dendrobium officinale. J Asian Nat Prod Res 17:125-131

19. Li Y, Wang CL, Zhao HJ, Guo SX (2014) Eight new bibenzyl derivatives from Dendrobium candidum. J Asian Nat Prod Res 16:1035-1043

20. Li Y, Wang CL, Guo SX, Yang JS, Xiao PG (2008) Two new compounds from Dendrobium candidum. Chem Pharm Bull 56:1477-1479

21. Yang D, Cheng ZQ, Yang L, Hou B, Yang J, Li XN, Zi CT, Dong FW, Liu ZH, Zhou J, Ding ZT, Hu JM (2018) Seco-dendrobinetype alkaloids and bioactive phenolics from Dendrobium findlayanum. J Nat Prod 81:227-235

22. Zhang C, Liu SJ, Yang L, Yuan MY, Li JY, Hou B, Li HM, Yang XZ, Ding CC, Hu JM (2017) Sesquiterpene amino ether and cytotoxic phenols from Dendrobium wardianum Warner. Fitoterapia 122:76-79

23. Li QM, Jiang H, Zha Q, Wu DL, Pan LH, Duan J, Liu J, Luo JP (2020) Anti-inflammatory bibenzyls from the stems of Dendrobium huoshanense via bioassay guided isolation. Nat Prod Res 34:563-566

24. Kuboki A, Yananoto T, Ohira S (2003) Total synthesis of $( \pm)$-aiphanol, a novel cyclooxygenase-inhibitory stilbenolignan. Chem Lett 32:420-421

25. Senthilkumar K, Kumaresan RA (2012) DFT study on the structural, electronic properties and radical scavenging mechanisms of calycosin, glycitein, pratensein and prunetin. Comput Theoret Chem 985:14-22

26. Bartmess JE (1994) Thermodynamics of the electron and the proton. J Phys Chem 98:6420-6424

27. Rimarcik J, Lukes V, Klein E, Ilcin M (2010) Study of the solvent effect on the enthalpies of homolytic and heterolytic N-H bond cleavage in phenylenediamine and tetracyano- $\mathrm{p}$-phenylenediamine. J Mol Struc: THEOCHEM 925:25-30

28. Wilhelm E, Battino R, Wilcock RJ (1977) Low-pressure solubility of gases in liquid water. Chem Rev 77:219-262

29. Frisch MJ, Trucks GW, Schlegel HB, Scuseria GE, Robb MA, Cheeseman JR, Scalmani G, Barone V, Mennucci B, Petersson GA, Nakatsuji H, Caricato M, Li X, Hratchian HP, Izmaylov AF, Bloino J, Zheng G, Sonnenberg JL, Hada M, Ehara M, Toyota K, Fukuda R, Hasegawa J, Ishida M, Nakajima T, Honda Y, Kitao
O, Nakai H, Vreven T, Montgomery JA, Peralta JE, Ogliaro F, Bearpark M, Heyd JJ, Brothers E, Kudin KN, Staroverov VN, Kobayashi R, Normand J, Raghavachari K, Rendell A, Burant JC, Iyengar SS, Tomasi J, Cossi M, Rega N, Millam JM, Klene M, Knox JE, Cross JB, Bakken V, Adamo C, Jaramillo J, Gomperts R, Stratmann RE, Yazyev O, Austin AJ, Cammi R, Pomelli C, Ochterski JW, Martin RL, Morokuma K, Zakrzewski VG, Voth GA, Salvador P, Dannenberg JJ, Dapprich S, Daniels AD, Farkas O, Foresman JB, Ortiz JV, Cioslowski J, Fox DJ (2009) Gaussian 09, Revision B.01, Gaussian, Inc., Wallingford CT

30. Xue YS, Zheng YG, An L, Dou YY, Liu Y (2014) Density functional theory study of the structure-antioxidant activity of polyphenolic deoxybenzoins. Food Chem 151:198-206

31. Leopoldini M, Chiodo SG, Russo N, Toscano M (2011) Detailed investigation of the $\mathrm{OH}$ radical quenching by natural antioxidant caffeic acid studied by quantum mechanical models. J Chem Theory Comput 7:4218-4233

32. Tomasi J, Mennucci B, Cammi R (2005) Quantummechanical continuumsolvation models. Chem Rev 105:2999-3094

33. Ng LT, Ko HH, Lu TM (2009) Potential antioxidants and tyrosinase inhibitors from synthetic polyphenolic deoxybenzoins. Bioorg Med Chem 17:4360-4366

34. Trouillas P, Marsal P, Siri D, Lazzaroni R, Duroux JL (2006) A DFT study of the reactivity of $\mathrm{OH}$ groups in quercetin and taxifolin antioxidants: the specificity of the 3-OH site. Food Chem 97:679-688

35. Nenadis N, Sigalas MP (2011) A DFT study on the radical scavenging potential of selected natural 3',4'-dihydroxy aurones. Food Res Int 44:114-120

36. Mazzone G, Malaj N, Russoa N, Toscano M (2013) Density functional study of the antioxidant activity of some recently synthesized resveratrol analogues. Food Chem 141:2017-2024

37. Xue YS, Zheng YG, Zhang L, Wu WY, Yu D, Liu Y (2013) Theoretical study on the antioxidant properties of 2'-hydroxychalcones: H-atom vs. electron transfer mechanism. J Mol Model 19:3851-3862

38. Lengyel J, Rimarcik J, Vaganekc A, Klein E (2013) On the radical scavenging activity of isoflavones: thermodynamics of $\mathrm{O}-\mathrm{H}$ bond cleavage. Phys Chem Chem Phys 15:10895-10903

39. Foti MC, Daquino C, Geraci C (2004) Electron-transfer reaction of cinnamic acids and their methyl esters with the DPPH radical in alcoholic solutions. J Org Chem 69:2309-2314

40. Musialik M, Litwinienko G (2005) Abnormal solvent effects on hydrogen atom abstraction 2. Resolution of the curcumin antioxidant controversy. The role of sequential proton loss electron transfer. Org Lett 7:4951-4954

41. Arshad MN, Mahmood T, Khan AF, Zia-Ur-Rehman M, Asiri AM, Khan IU, Ayub K, Mukhtar A, Saeed MT (2015) Synthesis, crystal structure and spectroscopic properties of 1,2-benzothiazine derivatives: an experimental and DFT study. Chin J Struct Chem 34:15-25

42. Wang BL, Zhu HW, Ma Y, Xiong LX, Li YQ, Zhao Y, Zhang JF, Chen YW, Zhou S, Li ZM (2013) Synthesis, insecticidal activities, and SAR studies of novel pyridylpyrazole acid derivatives based on amide bridge modification of anthranilic diamide insecticides. J Agric Food Chem 61:5483-5493

43. Liu XH, Chen PQ, Wang BL, Li YH, Wang SH, Li ZM (2007) Synthesis, bioactivity, theoretical and molecular docking study of 1-cyano-N-substituted-cyclopropanecarboxamide as ketol-acid reductoisomerase inhibitor. Bioorg Med Chem Lett 17:3784-3788

44. Sun NB, Fu JQ, Weng JQ, Jin JZ, Liu XH (2013) Microwave assisted synthesis, antifungal activity and DFT theoretical study of some novel 1,2,4-triazole derivatives containing the 1,2,3-thiadiazole moiety. Molecules 18:12725-12739

45. Scrocco E, Tomasi J (1978) Electronic molecular structure, reactivity and intermolecular forces: an euristic interpretation by means of electrostatic molecular potentials. Adv Quantum Chem $11: 115-193$ 
46. Santhosh C, Mishra PC (1994) Electrostatic potential and electric field mapping of some sweeteners of the suosan series: a search for the structure-activity relationship. Int J Quant Chem 51:335-341

47. Kumar A, Bhattacharjee AK, Mishra PC (1992) Electric-field mapping of some substituted 3-pyridinecarboxylic acid cardiotonics and the possible structure-activity relationships. Int J Quant Chem 43:L579-589
48. Wang J, Tang H, Hou B, Zhang P, Wang Q, Zhang BL, Huang YW, Wang Y, Xiang ZM, Zi CT, Wang XJ, Sheng J (2017) Synthesis, antioxidant activity, and density functional theory study of catechin derivatives. RSC Adv 7:54136-54141

Publisher's Note Springer Nature remains neutral with regard to jurisdictional claims in published maps and institutional affiliations. 